\title{
Stereospecific Alignment of the $\mathrm{X}$ and $\mathrm{Y}$ Elements Is Required for Major Histocompatibility Complex Class II DRA Promoter Function
}

\author{
BARBARA J. VILEN, ${ }^{1,2}$ JOHN P. COGSWELL, ${ }^{1}$ AND JENNY P.-Y. TING ${ }^{1,2 *}$ \\ Lineberger Cancer Research Center ${ }^{1}$ and Department of Microbiology-Immunology, ${ }^{2}$ University of \\ North Carolina at Chapel Hill, Chapel Hill, North Carolina 27599
}

Received 5 November 1990/Accepted 29 January 1991

\begin{abstract}
The regulatory mechanisms controlling expression of the major histocompatibility complex (MHC) class II genes involve several cis-acting DNA elements, including the $\mathrm{X}$ and $\mathrm{Y}$ boxes. These two elements are conserved within all murine and human class II genes and are required for accurate and efficient transcription from MHC class II promoters. Interestingly, the distance between the $X$ and $Y$ elements is also evolutionarily conserved at 18 to 20 bp. To investigate the function of the invariant spacing in the human MHC class II gene, HLA-DRA, we constructed a series of spacing mutants which alters the distance between the $X$ and $Y$ elements by integral and half-integral turns of the DNA helix. Transient transfection of the spacing constructs into Raji cells revealed that inserting integral turns of the DNA helix $(+20$ and +10 bp) did not reduce promoter activity, while inserting or deleting half-integral turns of the DNA helix $(+15,+5$, and $-5 \mathrm{bp})$ drastically reduced promoter activity. The loss of promoter function in these half-integral turn constructs was due neither to the inability of the $\mathrm{X}$ and $\mathrm{Y}$ elements to bind proteins nor to improper binding of the $\mathrm{X}$ - and $\mathrm{Y}$-box-binding proteins. These data indicate that the $X$ and $Y$ elements must be aligned on the same side of the DNA helix to ensure normal function. This requirement for stereospecific alignment strongly suggests that the $X$ - and Y-boxbinding proteins either interact directly or are components of a larger transcription complex which assembles on one face of the DNA double helix.
\end{abstract}

The interaction between nuclear proteins and DNA is fundamental to transcriptional regulation in eukaryotic cells (reviewed in references 37, 41, and 47). DNA-binding proteins further interact with one another, both at neighboring DNA sites and over long distances, to form complex networks of protein-DNA and protein-protein interactions (24, $46,48,60)$. Our knowledge of protein-DNA interactions is rapidly increasing as cis-acting DNA elements and their cognate sequence-specific binding proteins are identified in many eukaryotic systems $(28,37,41)$. Despite these advances in our understanding of protein-DNA interactions, much remains to be learned about protein-protein interactions and the complex network of interactions which control gene expression.

The class II major histocompatibility complex (MHC) antigens are involved in the initiation and control of the immune response (reviewed in references 29 and 54). These molecules function in the presentation of self and foreign antigens to class II-restricted, antigen-specific T cells $(4,52)$. Class II MHC molecules are expressed on a limited number of cells, including B cells, thymic epithelial cells, dendritic cells, glial cells, activated macrophages, and T cells $(25,51$, 57, 59). In addition, class II MHC expression can be induced by gamma interferon in a number of class II-negative cells such as endothelial cells and fibroblasts $(2,12,45)$. Expression of these genes is coordinated for the human DP, DQ, and DR $\alpha$ - and $\beta$-chain genes and the class II-associated invariant (Ii)-chain gene $(31,35,44)$. The coordinate, inducible, and cell-type-specific expression of class II molecules is tightly regulated (32). Complex regulation is necessary, as aberrant expression of these molecules has been implicated in immune dysfunction $(7,38,49)$. Because of their biological importance, there is great interest in understanding the

\footnotetext{
* Corresponding author.
}

mechanisms responsible for the regulation of $\mathrm{MHC}$ class II gene expression.

Within the $5^{\prime}$ promoter region of the MHC class II genes, several cis-acting regulatory sequences have been shown to function in inducible and basal gene expression $(11,14,53$, $55,56,61)$. The $\mathrm{X}$ element, $\mathrm{Y}$ element, and intervening spacer region, collectively called the class II box, are conserved in all murine and human class II genes and are required for accurate and efficient transcription from the MHC class II promoters, as demonstrated by transient transfection analysis, in vitro transcription studies, and transgenic mice studies $(18,53,64)$. Through gel mobility shift assays and screening of expression libraries, multiple $X$ - and $Y$-box-binding proteins have been identified $(6,9,15$, $17,34,42,50,55)$.

In all human and murine class II genes, the spacing between the $\mathrm{X}$ and $\mathrm{Y}$ elements is highly conserved at 18 to 20 bp but is variable in sequence (30). We hypothesized that this conserved, two-helical-turn spacing may be required to align the $X$ and $Y$ elements on the same side of the DNA helix, thereby allowing the $\mathrm{X}$ - and $\mathrm{Y}$-box-binding proteins to directly interact or to participate in the assembly of a larger promoter complex. A similar stereospecific alignment requirement between cis-acting promoter elements has been identified in both prokaryotic and eukaryotic systems.

In the simian virus 40 early promoter and the adenovirus type 2 E1b promoter, proper function requires correct stereospecific alignment of the GC boxes with the TATA element or the upstream enhancer sequence $(58,63)$. In RNA polymerase I-dependent transcription, transcription of the Xenopus ribosomal DNA gene is strongly affected by the stereospecific alignment between the upstream and core domains (43). The role of spacing has also been implicated in determining whether the U6 and 7SK RNA genes of Arabidopsis thaliana are transcribed by RNA polymerase I or RNA polymerase II (62). In the prokaryotic systems, spac- 
ing has been shown to be important in the repression of the ara, gal, and deo operons in Escherichia coli and in the proper function of $\lambda$ repressor $(13,20,26,27,36)$. Collectively, these studies imply that precise assembly of the preinitiation complex in both prokaryotes and eukaryotes requires protein-protein interactions.

In this report, we investigate the function of the conserved spacing between the $\mathrm{X}$ and $\mathrm{Y}$ boxes of the DRA promoter. To address this question, we altered the distance between the $\mathrm{X}$ and $\mathrm{Y}$ boxes by approximately integral (10-bp) or half-integral (5-bp) turns of the DNA helix. These alternately spaced DRA promoters were functionally assessed by transient transfection and $S 1$ nuclease analyses. These results indicate that promoter function can be drastically diminished when half-integral turns of the DNA helix are either inserted or deleted from the spacer region between the $X$ and $Y$ boxes. In contrast, promoter function is maintained, and actually enhanced, when integral turns of the helix are inserted into the $X, Y$ spacer region. Further studies reveal that loss of promoter function upon alterations of the stereospecific alignment between the $\mathrm{X}$ and $\mathrm{Y}$ elements is not due to the inability of these elements to bind proteins, nor does it affect which DNA residues are contacted by the sequencespecific DNA-binding proteins. These data strongly suggest that the loss of promoter function accompanied by altered stereospecific alignment of the $\mathrm{X}$ and $\mathrm{Y}$ boxes may be due to the inability of the $\mathrm{X}$ - and $\mathrm{Y}$-box-binding proteins to directly interact or to the inability of these proteins to participate in the assembly of a functional promoter-proximal transcription complex.

\section{MATERIALS AND METHODS}

Cell culture and transfection. Raji is a human Epstein-Barr virus-positive Burkitt's lymphoma cell line. Cells were grown in RPMI 1640 supplemented with $8 \%$ fetal calf serum and $2 \mathrm{mM}$ glutamine. Transient transfections were performed by electroporation as previously described (56).

Plasmids. Deletion mutants $5^{\prime} \Delta-56$ and $5^{\prime} \Delta-56 \mathrm{X}+\mathrm{Y}$ have been previously described (55). Briefly, 5' $\Delta-56$ contains 56 bp of 5 '-flanking sequences of the HLA-DRA gene fused to the bacterial chloramphenicol acetyltransferase (CAT) gene. $5^{\prime} \Delta-56 \mathrm{X}+\mathrm{Y}$ was obtained by linearizing $5^{\prime} \Delta-56$ with $\mathrm{XbaI}$, followed by treatment with Klenow enzyme to form blunt ends and insertion of a 50-bp oligonucleotide containing the wild-type DRA X element, 19-bp spacer, and the $Y$ element. The spacer constructs were made identically to $5^{\prime} \Delta-56 \mathrm{X}+\mathrm{Y}$ except that oligonucleotides containing spacers varying in length were used as inserts. Dideoxynucleotide sequencing was performed directly from the double-stranded plasmid to confirm the orientation of the oligonucleotide insert.

CAT assays. CAT activity was determined as previously described (56). Following visualization by autoradiography, CAT activity was quantitated by scintillation counting sections of the thin-layer chromatography plate containing the acetylated and unacetylated reaction products. Percent acetylation was calculated from the counts per minute in the acetylated spots compared with those in the total. Relative CAT activity was calculated by normalizing the percent acetylation of each construct to that of the wild-type $5^{\prime} \Delta$ $56 \mathrm{X}+\mathrm{Y}$ control, which was arbitrarily assigned a value of 1.00 .

S1 nuclease protection analysis. Total cellular RNA was prepared from Raji cells $24 \mathrm{~h}$ following transfection and analyzed by $\mathrm{S} 1$ nuclease protection assay as described previously $(5,10,40)$. The radiolabeled, antisense RNA probe used in this assay was derived from the pGEM-DRACAT plasmid (3). The probe encompasses $293 \mathrm{bp}$ of the DRA upstream region, including the start site for transcription, and $266 \mathrm{bp}$ of the CAT structural gene.

Nuclear extracts and competitor oligonucleotides. Nuclear extracts were prepared from Raji and Namalwa cells as previously described (16). Competitor oligonucleotides containing the spacing alterations were made by using the polymerase chain reaction as follows: $6.5 \times 10^{-5} \mathrm{pmol}$ of synthetic, single-stranded oligonucleotides encompassing the coding strand and $150 \mathrm{pmol}$ of primers complementary to the $5^{\prime}$ and $3^{\prime}$ ends of the coding and noncoding strands, respectively, were allowed to denature, anneal, and fill in through 30 cycles in a Cetus thermocycler. Reaction mixtures contained $50 \mathrm{mM} \mathrm{KCl}, 10 \mathrm{mM}$ Tris- $\mathrm{HCl}(\mathrm{pH} \mathrm{8.0)}, 1.5$ $\mathrm{mM} \mathrm{MgCl}_{2}, 0.01 \%$ gelatin, $0.01 \%$ Triton X-100, $0.25 \mathrm{mM}$ deoxynucleoside triphosphate, and $2 \mathrm{U}$ of Taq enzyme. Polymerase chain reaction products were extracted with phenol-chloroform, ethanol precipitated, heated to $95^{\circ} \mathrm{C}$, and then cooled slowly to room temperature to anneal the complementary strands. These double-stranded products were quantitated both by spectrophotometric reading at 260 $\mathrm{nm}$ and by relative intensity of ethidium staining on an agarose gel. The quality of the double-stranded products was assessed by electrophoresis through a $12 \%$ denaturing polyacrylamide gel and subsequent ethidium staining.

Double-stranded competitors, $\mathrm{X}+$ spacer and $\mathrm{Y}+$ spacer, are 36- and 33-bp oligonucleotides spanning either the $X$ box and spacer sequences or the $\mathrm{Y}$ box and spacer sequences. These oligonucleotides have been previously described in detail (55).

Electrophoretic mobility shift assays. The procedure has been described in detail $(22,23)$. Radiolabeled probes were prepared as previously described (56). Binding reaction mixtures were prepared in $20-\mu$ l volumes and contained 50 $\mathrm{mM} \mathrm{NaCl}, 1 \mathrm{mM}$ dithiothreitol, $0.5 \mathrm{mM}$ EDTA, $1 \mathrm{mM}$ Tris- $\mathrm{HCl}(\mathrm{pH} 7.6), 2.5 \mathrm{mM} \mathrm{MgCl}_{2}, 2 \mu \mathrm{g}$ of poly(dI$\mathrm{dC}) \cdot \operatorname{poly}(\mathrm{dI}-\mathrm{dC})$ (Pharmacia), $4 \mu \mathrm{g}$ of nuclear extract protein, and 80,000 counts of end-labeled oligonucleotide probe. Samples were incubated for $30 \mathrm{~min}$ at room temperature and then electrophoresed through a $6 \%$ polyacrylamide gel containing $25 \mathrm{mM}$ Tris- $\mathrm{HCl}, 190 \mathrm{mM}$ glycine, and $1 \mathrm{mM}$ EDTA. Competitor DNA was incubated with the nuclear extract 5 min before addition of labeled probe.

Methylation interference analysis. The procedure was performed as described previously (1), with the following modifications. Probes used in the binding reaction were prepared by end labeling one strand of a synthetic oligonucleotide with T4 polynucleotide kinase. Subsequently, the kinase enzyme was inactivated by boiling, equal molar amounts of the complementary strand were annealed, and the labeled double-stranded oligonucleotides were separated from unincorporated radionucleotides by passage over a NENSORB 20 nucleic acid purification column (New England Nuclear). Electrophoretic mobility shift reactions were scaled up eightfold and performed as described above. After a 2-h exposure at $-70^{\circ} \mathrm{C}$, the DNA-protein complexes and free probe were excised from the gel. The DNA was electrophoresed from the acrylamide strips by using a vertical electrophoresis apparatus and collected in SpectraPor 1000 dialysis membrane containing $250 \mu \mathrm{l}$ of $89 \mathrm{mM}$ Tris-borate-2 mM EDTA ( $\mathrm{pH} \mathrm{8.0)}$ buffer. Following phenol-chloroform extractions and ethanol precipitation, the DNA was resuspended in $20 \mu$ l of distilled $\mathrm{H}_{2} \mathrm{O}$. Piperidine cleavage was performed at $95^{\circ} \mathrm{C}$ for $20 \mathrm{~min}$ by adding $25 \mu$ of $2 \mathrm{M}$ piperidine to each DNA sample. Following cleavage, sam- 


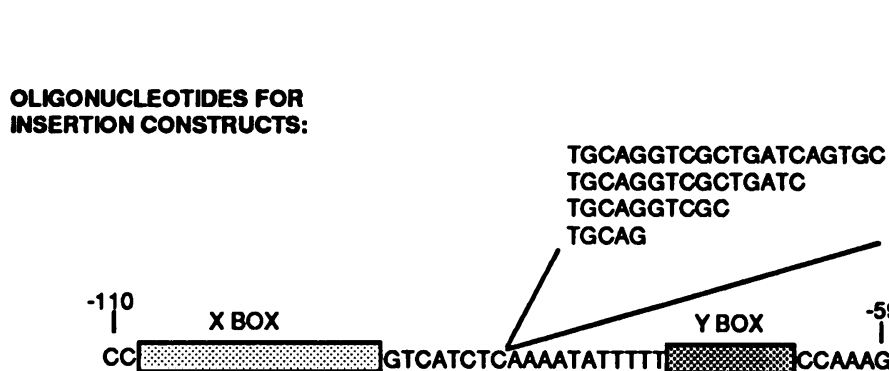
GTCATCTCAAAATATTTTT CCAAG

\section{CONSTRUCT NAME}

PSPACER + 20 PSPACER +15 PSPACER +10 PSPACER + 5

$5 \Delta-56 X+Y$

\section{SPACING BETWEEN X\&Y}

HELCAL

TURNS (APPROXIMATE)
4.0

3.0

$24 \mathrm{bp}$

$19 \mathrm{bp}$

OLGONUCLEOTIDES FOR DELETION CONSTRUCTS:
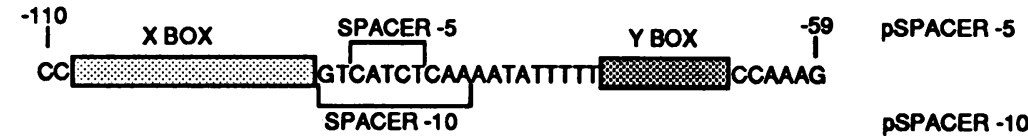

14 bp

1.5

9 bp

1.0

FIG. 1. Plasmid constructs of the HLA-DRA promoter containing altered spacing between the $\mathrm{X}$ and $\mathrm{Y}$ elements. Oligonucleotides used for insertion and deletion constructs are shown. Nucleotides are numbered relative to the transcriptional start site. All insertions are made at position $-\mathbf{8 5} \mathrm{bp}$ of an otherwise unaltered DRA promoter. Deletion constructs were made by removing bracketed nucleotides. Construct name represents circular plasmid after mutated oligonucleotides were cloned into the $5^{\prime} \Delta-56$ plasmid. Spacing between $X$ and $Y$ reflects the total number (the wild-type $19 \mathrm{bp}$ and any insertions or deletions) of nucleotides separating the two elements. Approximate number of helical turns was calculated on the basis of 10 nucleotides per turn of the DNA double helix. $5^{\prime} \Delta-56 \mathrm{X}+\mathrm{Y}$ represents the wild-type control.

ples were precipitated by adding $1 \mathrm{ml}$ of sec-butanol, spun at $10,000 \mathrm{rpm}$ for $5 \mathrm{~min}$, resuspended in $50 \mu \mathrm{l}$ of $0.1 \%$ sodium dodecyl sulfate, reprecipitated with sec-butanol, then washed with $200 \mu \mathrm{l}$ of $100 \%$ ethanol. Samples were resuspended in formamide loading buffer, heated to $95^{\circ} \mathrm{C}$ for 5 min, and then loaded on a $12 \%$ polyacrylamide- $8 \mathrm{M}$ urea wedge gel.

\section{RESULTS}

Proper spacing between the $X$ and $Y$ boxes is required for HLA-DRA promoter function. We have previously shown that the $X$ and $Y$ elements are required for proper DRA function, since mutation of either the $X$ element or the $Y$ element results in a reduction in promoter function to 67 or $51 \%$ of control, respectively (55). To evaluate the role of the conserved 19-bp spacer which separates the $X$ and $Y$ elements in DRA promoter function, we constructed a series of spacing mutants which alter the distance between the $X$ and $\mathrm{Y}$ boxes by integral and half-integral turns of the DNA helix (Fig. 1). The insertion constructs contain nucleotide insertions of $20 \mathrm{bp}(\mathrm{pSpacer}+20), 15 \mathrm{bp}(\mathrm{pSpacer}+15), 10 \mathrm{bp}$ $(\mathrm{pSpacer}+10)$, or $5 \mathrm{bp}(\mathrm{pSpacer}+5)$, representing $2.0,1.5$, 1.0 , or 0.5 additional turn of the DNA helix, respectively. All insertions were made at position $-85 \mathrm{bp}$ of an otherwise unaltered -110-bp DRA promoter fragment. Similarly, the deletion constructs have 10 bp (pSpacer-10) or 5 bp (pSpacer-5) removed from the spacer region, representing a loss of 1.0 or 0.5 turn of the DNA helix. Alterations of the spacer between $X$ and $Y$ by 0.5 or 1.5 turns of the helix would align the $X$ and $Y$ elements on the opposite side of the DNA helix, thereby abolishing any interactions which require the $\mathrm{X}$ - and $\mathrm{Y}$-box-binding proteins to bind on the same side of the double helix. Likewise, alterations of the spacer by one or two complete helical turns would change the distance between the $X$ and $Y$ boxes, but the two elements would remain on the same side of the DNA helix.

To assess DRA promoter activity, the various spacer mutants and the wild-type control $\left(5^{\prime} \Delta-56 \mathrm{X}+\mathrm{Y}\right)$ were transiently transfected into Raji cells, a B lymphoblastoid cell line that constitutively expresses high levels of HLA-DRA transcripts. The mean CAT activities of five independent transfections are shown in Fig. 2. As previously reported, substantial DRA promoter activity was observed with the construct $5^{\prime} \Delta-56 \mathrm{X}+\mathrm{Y}$, which contains the wild-type class II box (56). This control yields an average acetylation of $20 \%$. When integral turns of the DNA helix were inserted into the $X, Y$ spacer region, DRA promoter activity was increased above the value for the wild-type control. Transfection with pSpacer +20 resulted in CAT activity $1.68 \pm 0.27$-fold that of the wild-type control, while pSpacer +10 activity was $1.37 \pm$ 0.30 -fold that of the wild-type control (Fig. 2). In contrast, insertion or deletion of half-integral turns of the DNA helix, represented by pSpacer +15 , pSpacer +5 , and pSpacer -5 , showed markedly diminished promoter activity. Unexpectedly, deletion of $10 \mathrm{bp}$ from the spacer also diminished promoter activity to $53 \%$ of the control value. The pSpacer -10 construct maintains the $X$ and $Y$ elements on the same side of the DNA helix but brings the two elements to within $9 \mathrm{bp}$ of one another. Loss of promoter activity with this construct may have occurred because the $\mathrm{X}$ - and $\mathrm{Y}$-box protein binding sites have been brought too close together for proper assembly of a functional promoter-proximal transcription complex. Another possibility is that a recently defined human X-box-binding protein (hXBP-1) contact residue has been deleted, possibly destabilizing or interfering with X-box binding (33). Nonetheless, the ability of pSpacer +20 and pSpacer +10 , and the inability of pSpacer +15 , pSpacer +5 , and pSpacer -5 , to be efficiently transcribed is coincidental with the number of helical repeats between the $\mathrm{X}$ and $\mathrm{Y}$ elements.

To determine whether the transient transfection results are observed at the RNA level, S1 nuclease protection analyses were performed to map the transcriptional start site and to quantitate the levels of correctly initiated transcripts (Fig. 3). The riboprobe used in the S1 nuclease analyses 


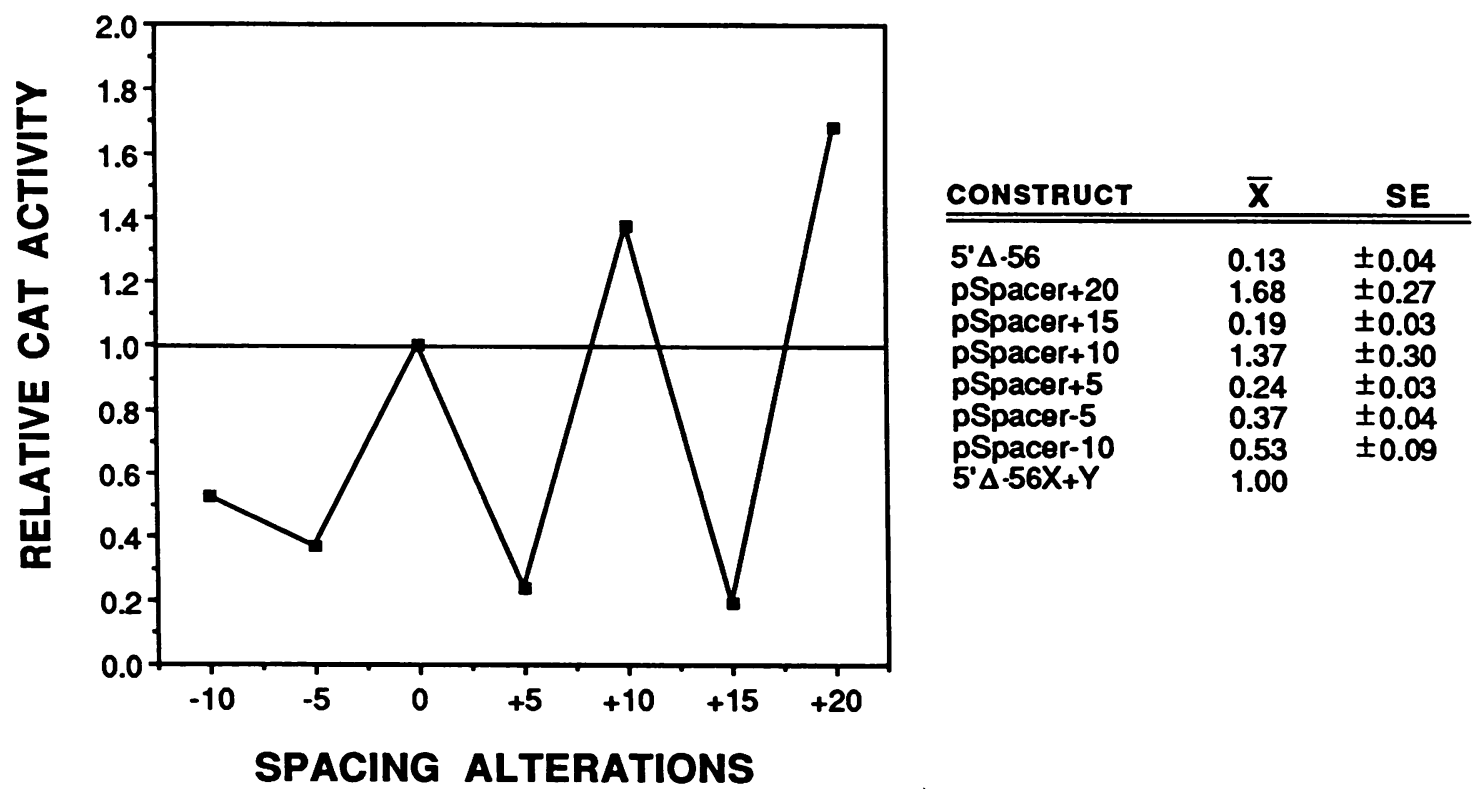

FIG. 2. Effect of helical alterations on DRA promoter function. The data are presented as relative CAT activity versus spacing alterations. Relative CAT activity was determined by normalizing the percent acetylation of the chloramphenicol substrate to that of the 5 ' $\Delta-56 \mathrm{X}+\mathrm{Y}$ wild-type control, which was arbitrarily assigned a value of 1.00 . The $5^{\prime} \Delta-56 \mathrm{X}+\mathrm{Y}$ wild-type control is represented on the $x$ axis as 0 spacing, and all other spacing constructs are represented as the number of nucleotides inserted or deleted from the spacer region. Each point on the graph represents the mean of five independent experiments. $X$, Mean of the normalized values; SE, standard error of the mean. The data points in the graph correspond to the $\mathrm{X}$ value shown for each construct in the table at the right.

consists of $266 \mathrm{bp}$ of DRA promoter sequence, the cap site, $27 \mathrm{bp}$ of DRA sequence $3^{\prime}$ to the cap site, and $266 \mathrm{bp}$ of the CAT structural gene (3). Correctly initiated transcripts from the DRA-CAT constructs protect a 293-bp fragment (Fig. 3B) from $S 1$ digestion. Quantitation of the correctly initiated transcripts from the spacer mutants and the wild-type control (Fig. 3B, lanes 2 to 8 ) reveals a pattern similar to that seen in the transient transfection assay (Fig. 3A, lanes 2 to 8). Again, pSpacer +20 and pSpacer +10 showed greater levels of DRA-specific transcripts in comparison with pSpacer +15 , pSpacer +5 , and pSpacer -5 , while pSpacer-10 showed intermediate levels of transcripts in comparison with the wild-type control. These data confirm that the cyclic changes observed at the protein level directly reflect accurate transcriptional activity from the mutant DRA promoters. Other control lanes include $5^{\prime} \Delta-56$, which lacks the class II box, and tRNA, which does not hybridize to the antisense probe (Fig. 3B, lanes 1 and 9, respectively).

Nuclear proteins bind the class II box regardless of spacing alterations. Transcription from the DRA promoter requires multiple protein factors which bind the $\mathrm{X}$ and $\mathrm{Y}$ elements $(6$, $9,15,17,34,42,50)$. To determine whether the loss of promoter function upon misalignment of the $\mathrm{X}$ and $\mathrm{Y}$ boxes is due to the loss of protein binding to these elements, we first performed competition assays. A 50-bp oligonucleotide encompassing the wild-type DRA class II box was radiolabeled and allowed to react with nuclear proteins prepared from Namalwa B cells (identical results were obtained with Raji and HeLa nuclear extracts). Four specific protein-DNA complexes labeled B1, B2/B3, and B4 were formed (Fig. 4A, lane 1; Fig. 4B, lane 1). The complex labeled B2/B3 appears as a single band in this particular experiment but has been reproducibly shown to resolve as a doublet (data not shown). To show specificity of the protein-DNA complexes, competition with a 50-fold molar excess of homologous unlabeled

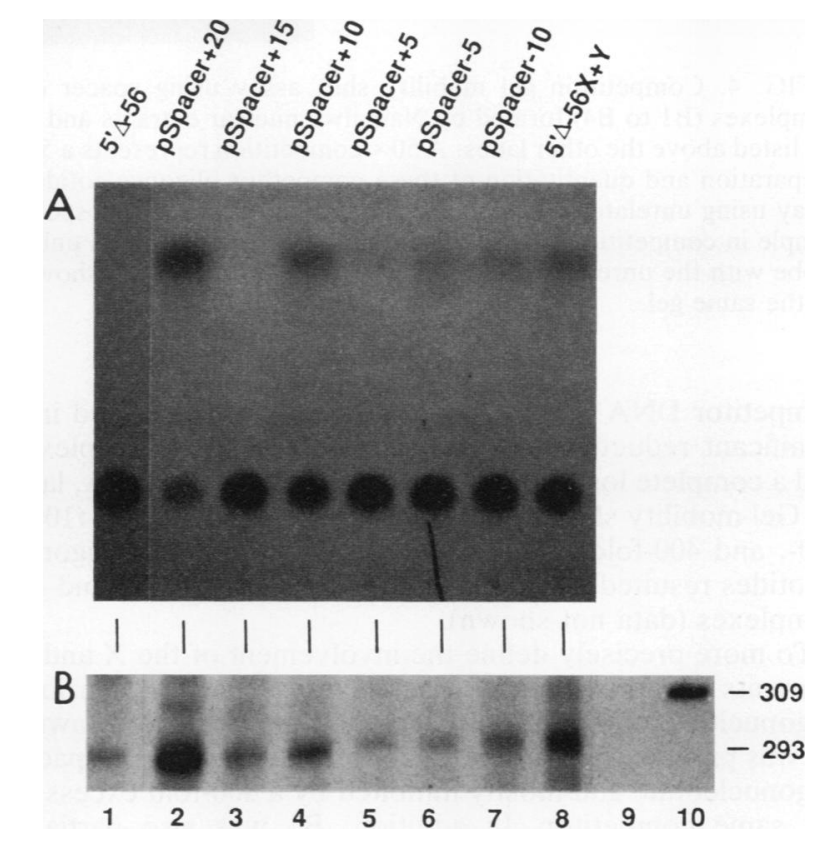

FIG. 3. Promoter function of spacing constructs analyzed by $\mathrm{S} 1$ nuclease protection analysis. (A) CAT assay; (B) S1 nuclease protection experiment. The plasmids used to transfect Raji cells before RNA isolation are listed above the lanes. RNA was isolated $24 \mathrm{~h}$ after transfection, and S1 analysis was performed. Lanes 1 to 8 of the CAT assay correspond to lanes 1 to 8 of the $S 1$ analysis. The same controls were used for both assays. Lane 9 of the S1 analysis represents a tRNA control. The markers (lane 10) are end-labeled fragments of HpaIl-cut plasmid pBR322. The 309-bp marker fragment and the authentic 293-bp transcript are marked. Assays of juxtaposed lanes were performed within the same experiment. 


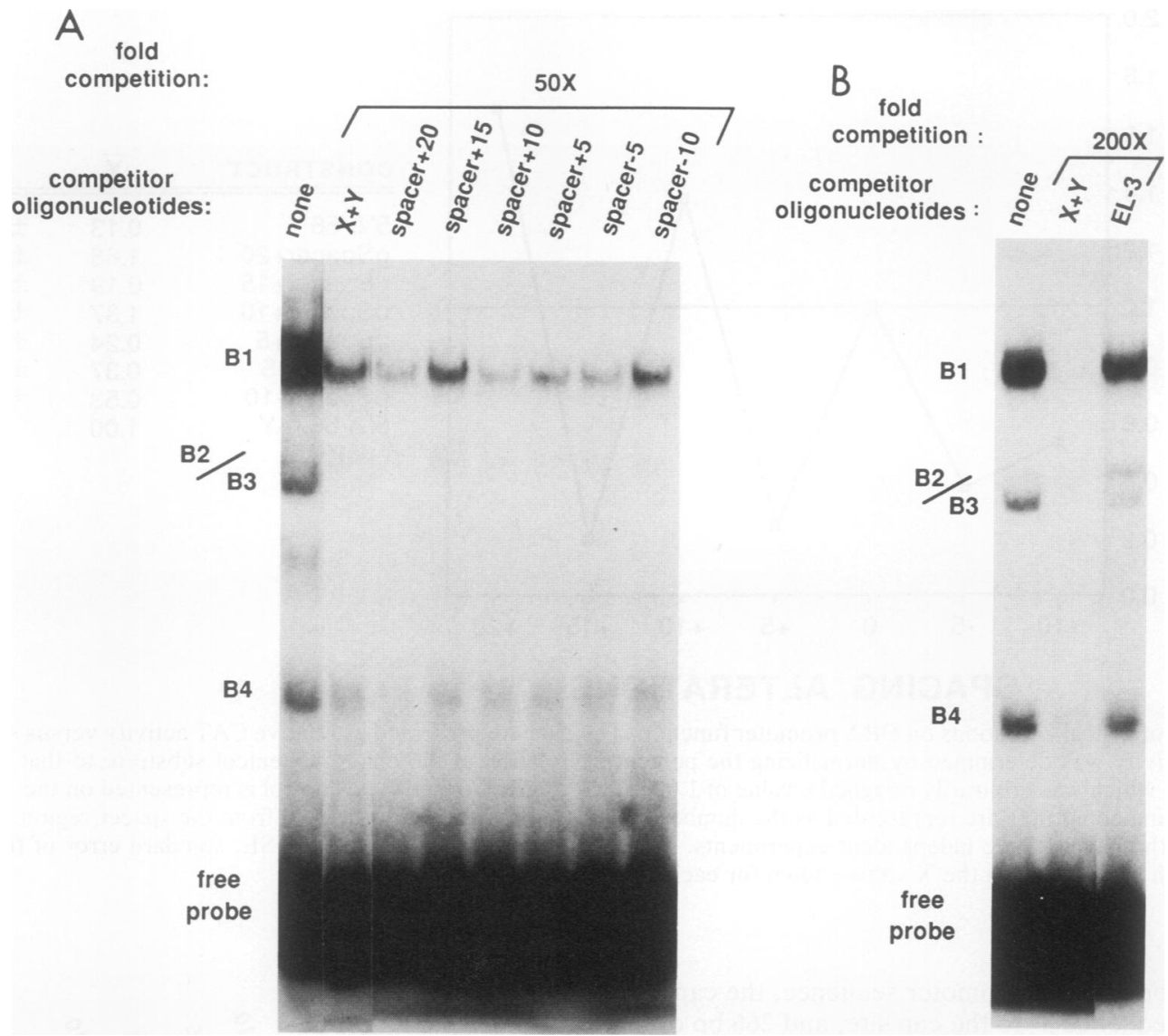

FIG. 4. Competition gel mobility shift assay using spacer oligonucleotides. In panel A, the left-most lane shows the DNA-protein complexes (B1 to B4) formed by Namalwa nuclear extracts and the wild-type X, spacer, and $\mathrm{Y}(\mathrm{X}+\mathrm{Y})$ probe. Competitor oligonucleotides are listed above the other lanes. A $50 \times$ competition represents a 50-fold molar excess of the unlabeled oligonucleotide shown above each lane. Preparation and quantitation of these competitor oligonucleotides are described in detail in Materials and Methods. (B) Gel mobility shift assay using unrelated EL-3 competitor. Lanes 1 and 2 correspond respectively to the uncompeted X+Y protein-DNA complexes and to a sample in competition with a 200 -fold excess of homologous unlabeled $X+Y$ competitor. Lane 3 shows a 200-fold competition of the $X+Y$ probe with the unrelated EL-3 competitor. Panels A and B show separate experiments, although all samples in each panel were performed on the same gel.

competitor DNA $(\mathrm{X}+\mathrm{Y})$ was performed. This resulted in a significant reduction of the specific $\mathrm{B} 1$ and $\mathrm{B} 4$ complexes and a complete loss of the weaker B3 complex (Fig. 4A, lane 2). Gel mobility shift competition assays using greater (100-, 200-, and 400-fold) molar excesses of competitive oligonucleotides resulted in complete elimination of the B1 and B4 complexes (data not shown).

To more precisely define the involvement of the $\mathrm{X}$ and $\mathrm{Y}$ elements in formation of complexes $\mathrm{B} 1$ to $\mathrm{B} 4$, various oligonucleotides were used as competitors (data not shown). B1 was partially inhibited by a 50 -fold excess of a $\mathrm{Y}+$ spacer oligonucleotide and mostly inhibited by a 200 -fold excess of the same competitor. In addition, B1 was also partially inhibited by a 200 -fold but not a 50-fold excess of a $\mathrm{X}+$ spacer oligonucleotide. This result suggests that the $\mathrm{Y}$ element is a predominant contributor to the formation of this complex, while the $\mathrm{X}$ element may also play a role. This conclusion agrees with the methylation interference analysis shown below. Analysis of column-fractionated B2 shows that it could be inhibited by $\mathrm{Y}+$ spacer but not $\mathrm{X}+$ spacer, suggesting that it consists of a protein complex formed with the Y element (63a). B3 could be inhibited by $X+$ spacer but not $\mathrm{Y}+$ spacer, suggesting that it involves complex formation with the $\mathrm{X}$ element. B4 most likely represents complex formation with the $X$ element because a 50 -fold excess of a $\mathrm{X}+$ spacer oligonucleotide blocked the formation of this complex, but a similar oligonucleotide with mutated $\mathrm{X}$ element was ineffective.

To assess the capacity of the $\mathrm{X}$ and $\mathrm{Y}$ elements to bind nuclear proteins when separated by distances other than the conserved 19-bp spacer, the oligonucleotides containing spacer alterations were used as competitors in the gel shift assay. These spacer competitors were prepared by polymerase chain reaction amplification from the oligonucleotides shown in Fig. 1. These oligonucleotides have insertions and deletions within the spacer region and correspond to the oligonucleotides used to generate the pSpacer constructs. The competitors were quantitated by spectrophotometric readings and by ethidium staining of agarose and polyacrylamide gels because accurate quantitation is critical for allowing direct comparison between the different competitors. Competition gel shift analysis was performed by first allowing the nuclear extract to react with unlabeled competitor DNA. Subsequently, the radiolabeled probe $(X+Y)$ was added and the protein-DNA complexes were separated by gel electrophoresis. The unlabeled competitor DNA would 
be expected to compete for nuclear proteins unless proper stereospecific alignment is required for protein binding.

Competition with a 50 -fold molar excess of each of the altered spacer oligonucleotides resulted in a significant reduction of all four protein-DNA complexes (Fig. 4A; compare lanes 3 to 8 with lane 1), whereas competition with an unrelated competitor did not diminish any of the specific complexes (Fig. 4B; compare lane 3 with lane 1). This finding indicates that stable binding of the $\mathrm{X}$ - and $\mathrm{Y}$-box-binding proteins can occur regardless of the relative helical orientation between the $\mathrm{X}$ and $\mathrm{Y}$ elements and that protein binding to the class II box is not sufficient for DRA promoter function.

Notably, all of the oligonucleotides containing spacing alterations could compete for $\mathrm{X}$ - and $\mathrm{Y}$-box-binding proteins, but careful serial dilution of the spacer competitors revealed subtle differences in their quantitative ability to compete for the B1 DNA-protein complex (Fig. 4A; compare lanes 3 to 8 with lane 2). These subtle differences were consistently seen with three batches of cold competitors that had been independently prepared, suggesting that the differences are not due to small errors in competitor quantitation. Curiously, densitometric scanning (data not shown) of B1 in the gel mobility shift assay revealed that although all constructs could compete at least as well as the wild-type control, pSpacer +20 and pSpacer +10 were better competitors than the other constructs. This result parallels their functional activity showing that pSpacer +20 and $\mathrm{pSpacer}+10$ were functionally more active than the wild-type control (Fig. 2). Whether these subtle differences in the ability to bind protein have any functional importance requires further examination.

Loss of promoter function is not due to altered protein-DNA contact points. The gel shift analysis clearly shows that $X$ and $Y$ proteins can bind the class II boxes regardless of helical alterations. To determine whether changes in the alignment of $\mathrm{X}$ and $\mathrm{Y}$ affect correct nucleotide contact points, and hence promoter function, we performed methylation interference analysis. We mapped the guanosine residues which, when methylated, interfere with protein binding. This analysis was done with the functional (spacer+10) and less functional (spacer +5 ) oligonucleotides, and these contact residues were compared with the contacts of the wild-type $\mathrm{X}+\mathrm{Y}$ oligonucleotide (Fig. 5). We have previously reported that the $\mathrm{B} 1$ complex protects the $\mathrm{Y}$ element on both the coding and noncoding strands, with inconsistent protection over the $X$ element on the noncoding strand (55). Here we have found that methylation of the $X+Y$ probe consistently interferes with complex formation at both the $X$ and $Y$ elements on the noncoding strand and at only the $\mathrm{Y}$ element of the coding strand (Fig. 5A), implying that B1 is a complex formed by proteins binding the $\mathrm{X}$ and $\mathrm{Y}$ elements. These observations have been confirmed by densitometric analysis (data not shown). Our ability to detect consistent interference over the $X$ region is a result of different batches of poly(dI-dC) and altered gel shift conditions which optimize protein binding. The methylation interference pattern of the B1 complex formed by spacer +5 was found to have contact residues identical to those of the wild-type $\mathrm{X}+\mathrm{Y}$ probe (Fig. $5 \mathrm{~A}$ and $\mathrm{B})$. However, the interference patterns of the $\mathrm{B} 1$ complex formed with the spacer +10 probe showed two additional weak contact points (Fig. 5C). These contacts were consistent for two independent experiments, suggesting that separation of the $\mathrm{X}$ and $\mathrm{Y}$ elements by an additional $10 \mathrm{bp}$ allows the $\mathrm{X}$ - and $\mathrm{Y}$-box-binding proteins to contact their cognate DNA elements at additional residues, possibly forming a more stable protein-DNA complex. Since the pSpacer +10 construct functions better than the $5^{\prime} \Delta-56 \mathrm{X}+\mathrm{Y}$ control, we suspect that this altered protein-DNA interaction may facilitate better transcription. Attempts to identify the contact points of the B2, B3, and B4 bands were unsuccessful because of their relatively weak binding. These data (Fig. 5D) indicate that the loss of promoter activity in the $\mathrm{pSpacer}+5$ construct is not due to the inability of the $\mathrm{X}$ and $Y$-box-binding proteins to correctly contact the $X$ and $Y$ elements. In addition, the increased promoter activity of the pSpacer +10 construct may be due to increased stability of the $\mathrm{X}-\mathrm{Y}$ complex, since additional protein-DNA contact points have been identified with this construct.

\section{DISCUSSION}

Although the proximal cis-acting elements involved in the activity of the MHC class II promoters have been defined, the protein-protein interactions which are necessary to achieve the complex regulation of class II expression are not well understood. Our insertion and deletion constructs were designed to address whether the conserved 19-bp spacing between the $\mathrm{X}$ and $\mathrm{Y}$ elements was necessary to allow protein-protein interactions within the proximal region of the DRA promoter. Studies using these constructs clearly show that proper DRA promoter function requires the $X$ and $Y$ elements to be stereospecifically aligned. Insertion constructs, with distances separating the $\mathrm{X}$ and $\mathrm{Y}$ elements by $39 \mathrm{bp}(\mathrm{pSpacer}+20)$ and $29 \mathrm{bp}(\mathrm{pSpacer}+10)$, create protein recognition sites which are aligned on the same side of the DNA helix, as is the case for the wild-type 19-bp spacer. The ability of these constructs to function at least as well as the wild-type construct may be explained in that stereospecific alignment between the two elements allows the $X$ - and $Y$-box-binding proteins to either interact directly or participate in the assembly of a larger promoter complex. In contrast, constructs containing $34 \mathrm{bp}$ (pSpacer +15$), 24 \mathrm{bp}$ $(\mathrm{pSpacer}+5)$, or $14 \mathrm{bp}(\mathrm{pSpacer}-5)$ would position the $\mathrm{X}$ and Y elements on opposite sides of the helix, thereby abolishing their ability to interact directly or indirectly. Modeling of the contact points identified by methylation interference analysis clearly shows the stereospecific alignment of the $\mathrm{X}$ and $\mathrm{Y}$ boxes when integral and half-integral turns separate these elements (Fig. 6). The contact points identified by methylation interference are depicted by arrows and then plotted on the double helix. In the wild-type $X+Y$ construct, the contact points fall on the same face of the double helix. The same would be true of the pSpacer +10 construct. In contrast, plotting the contact points in pSpacer +5 reveals that the $\mathrm{X}$ - and $\mathrm{Y}$-box-binding proteins would be oriented on opposite sides of the double helix. The same results would be predicted with the pSpacer +15 , pSpacer +5 , and pSpacer -5 constructs. This would explain the inability of these constructs to promote transcription. The conservation of the $\mathrm{X}$ and $\mathrm{Y}$ elements and the need for proper spacing between these elements strongly suggest that the $X$ - and Y-box-binding proteins are involved either directly or indirectly as components of a larger transcription complex. However, we cannot exclude the possibility that the stereospecific alignment between the $X$ box and further-downstream elements such as the octamer or the TATA element is important.

It is noteworthy that the methylation interference pattern of $B 1$ coincides with that of hXBP-1 (33) on the X element and the biochemically purified YEBP on the Y element (the relationship between the human YEBP and the cloned 

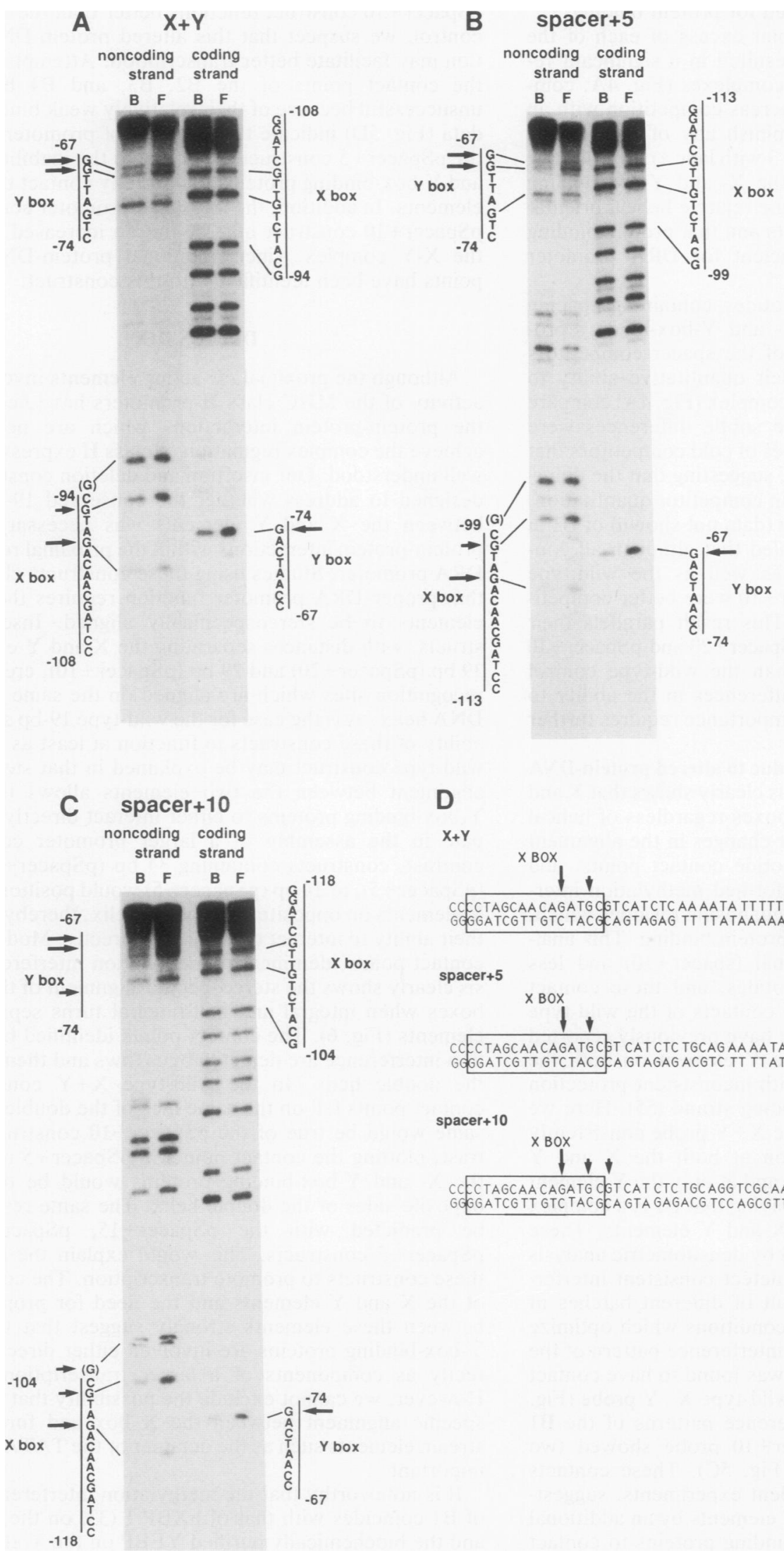

D

$X+Y$

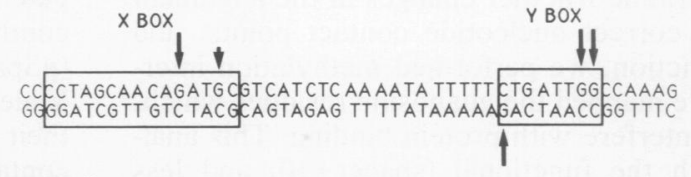

spacer+5

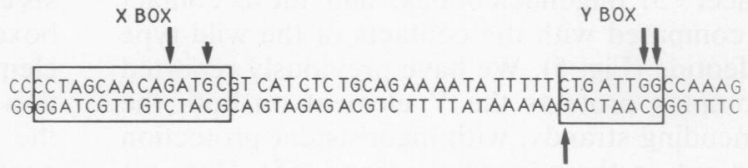

spacer +10

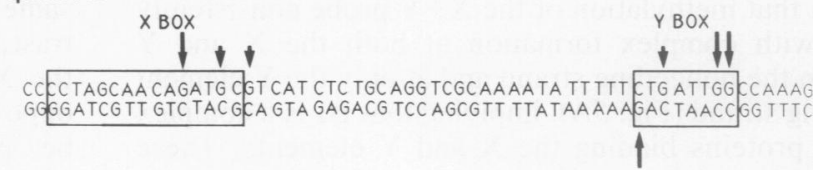



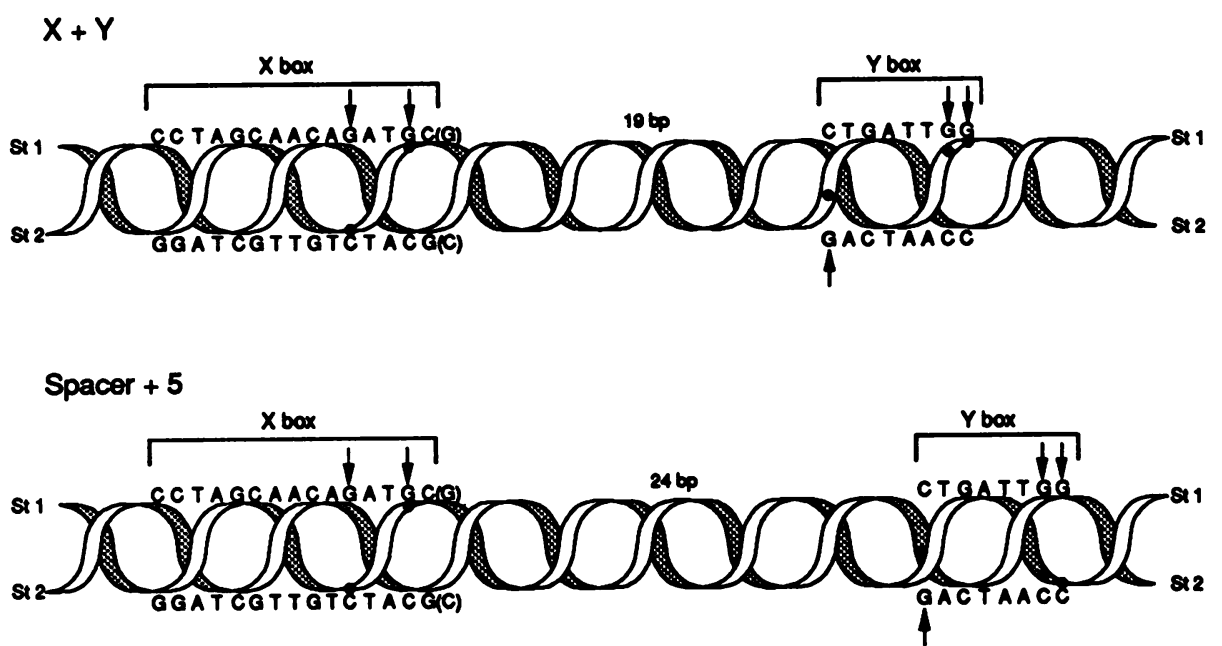

FIG. 6. Modeling of the stereospecific alignment between the $X$ and $Y$ elements in the wild-type $X+Y$ and the spacer +5 oligonucleotides. The DNA sequences of the $X$ and $Y$ elements on both the coding and noncoding strands are shown to scale on a double helix. The black dots within the DNA helix are accurately plotted and represent the contact residues of X-and Y-box-binding proteins as determined in the methylation interference analysis (most likely hXBP-1 and YEBP proteins). These contact points are also indicated by the arrow marking the DNA sequence. The shaded portion depicts the back side of the double helix, and the white portion represents the front of the helix. The guanosine residue shown in parentheses on strand 1 is within the spacer sequence.

murine NF-Y clones has not been determined, although they are most likely homologous). These data suggest that this complex consists of both $\mathrm{X}$ - and $\mathrm{Y}$-element-binding proteins. Interestingly, according to the model depicted in Fig. 6, the contact points of hXBP-1 and YEBP are actually stereospecifically aligned on the same phase of the DNA. In contrast, binding of another X-element-specific protein (RF-X) would result in this $\mathrm{X}$-element-binding protein being on the opposite side of the DNA double helix relative to the Y-elementbinding protein. We speculate that hXBP-1 and YEBP are aligned so that interactions between them could occur; however, direct experimentation is required to reach this conclusion.

The model that the $\mathrm{X}$ and $\mathrm{Y}$ elements must be stereospecifically aligned for DRA function is further supported by analysis of the MHC class II-associated Ii-chain promoter. Expression of MHC class II $\alpha$ - and $\beta$-chain genes is coordinately regulated with expression of the Ii-chain gene. The mechanism of this coordinate regulation is not clear, but recently $\mathrm{X}$ and $\mathrm{Y}$ homologs have been identified as functional cis-acting elements of the Ii-chain promoter $(8,19,21$, 65). Paradoxically, the $X$ and $Y$ elements within the Ii-chain promoter are separated by a 14-bp spacer. Careful analysis of the critical CCAAT residues within the Y element reveals that the Ii-chain and DRA CCAAT sequences are on opposite strands. This would maintain the stereospecific alignment between the $\mathrm{X}$ and $\mathrm{Y}$ elements within the Ii-chain promoter (8).

The constructs pSpacer $+20, \mathrm{pSpacer}+10$, and pSpacer -10 were used to address whether there is a distance as well as orientation requirement. It could be predicted that if stereospecific alignment were the only requirement for $X$ and $Y$ function, then any number of integral turns separating the $X$ and $\mathrm{Y}$ elements would confer function to the promoter, yet all murine and human class II genes have evolutionarily conserved this distance at approximately two turns of the DNA helix. We found that pSpacer +20 and pSpacer +10 function slightly better than the wild-type $5^{\prime} \Delta-56 \mathrm{X}+\mathrm{Y}$ construct and that pSpacer -10 functions at $53 \%$ of control. The ability of pSpacer +20 and pSpacer +10 to function suggests that it is relative helical orientation rather than precise spacing that is most important in DRA promoter function. One possible explanation for the enhanced function of pSpacer +20 and pSpacer +10 is that these constructs are able to form a more stable protein-protein (or multiprotein) complex than can the wild-type control. Evidence supporting this mechanism is revealed in the gel mobility shift competition experiment (Fig. 4). Here we have found that spacer +20 and spacer +10 compete more efficiently for the $\mathrm{X}$ - and Y-box-binding proteins than does the wild-type control. This mechanism is further supported by the methylation interference analysis showing that spacer +10 shows weak interference at additional guanosine residues compared with the wild-type $X+Y$ and spacer +5 probes (Fig. $5 \mathrm{C})$. The ability of the $\mathrm{X}$ - and $\mathrm{Y}$-box-binding proteins to contact additional residues may result in a more stable protein-protein complex. Expansion of distance between two promoter elements leading to increased promoter function has been previously seen in the thymidine kinase gene of herpes simplex virus (39).

FIG. 5. Methylation interference analysis of the B1 complex. Panels A, B, and C correspond to X+Y wild-type oligonucleotide, spacer +5 oligonucleotide, and spacer +10 oligonucleotide, respectively. $X$ and $Y$ consensus sequences are shown, and guanosine residues are marked by lines to the corresponding band in the gel. Nucleotides are numbered relative to the cap site. Numbering of the spacer mutants (spacer +5 and spacer +10$)$ reflect 5 - and 10-bp insertions. A longer arrow depicts residues where methylation strongly interferes with protein binding. A shorter arrow depicts residues where binding is weakly interfered with. The guanosine residue in parentheses next to the $\mathrm{X}$ element of the noncoding strand represents the most $5^{\prime}$ residue of the spacer sequence and is not part of the $X$ consensus sequence. On the noncoding strand of panel C, this residue appears as a doublet. This is an artifact due to cracking of the gel upon drying. Lanes: B, bound DNA; F, free DNA. (D) Summary of the data contained in panels A to C. Arrow size reflects strong versus weak interference. 
In light of the evidence presented here, it is apparent that considerable changes in the distance between the $X$ and $Y$ elements can be tolerated. Formation of a functional promoter complex, either through direct or indirect $\mathrm{X}-\mathrm{Y}$ interaction, requires that the proteins be flexible enough to compensate for the additional distance between these elements. Alternatively, the intervening DNA must be flexible enough to loop out and allow the $\mathrm{X}$ - and Y-box-binding proteins to form a functional promoter complex. It seems unlikely that the $\mathrm{X}$ - and $\mathrm{Y}$-box-binding proteins could compensate for an increased distance of two DNA helical turns, although this possibility cannot be excluded. A more likely explanation is that the spacer DNA is flexible enough to allow the intervening DNA to form a loop structure. In the 19-bp wild-type spacer, the distance may be close enough that looping is not required, but as the distance increases, the proteins could continue to interact if their binding sites are located on the same side of the double helix, by looping of the intervening DNA. This difference may account for the differences in the methylation interference patterns of spacer +10 and the wild-type control. In some systems in which stereospecific alignment between cis-acting elements is required, considerable length alterations have also been noted, suggesting direct interaction with looping of the intervening spacer DNA $(27,58)$.

Taken together, our data clearly demonstrate that the conserved 19-bp spacer found in the DRA promoter functions to stereospecifically align the $\mathrm{X}$ and $\mathrm{Y}$ elements. This requirement for stereospecific alignment suggests either that direct protein-protein interactions occur between the $X$ - and Y-box-binding proteins or that the $\mathrm{X}$ - and $\mathrm{Y}$-box-binding proteins need to be stereospecifically aligned for proper assembly of a larger promoter complex. Because all murine and human MHC class II genes have evolutionarily conserved the $X$ and $Y$ boxes and the two-helical-turn spacer, we predict that an interaction involving the $\mathrm{X}$ - and $\mathrm{Y}$-boxbinding proteins is a universal requirement in the regulation of all MHC class II genes. Future studies will be directed at identifying which of the $\mathrm{X}$ - and $\mathrm{Y}$-box-binding proteins participate in this interaction and assessing the role of the other $\mathrm{X}$ - and Y-box-binding proteins in the transcriptional regulation of the DRA promoter.

\section{ACKNOWLEDGMENTS}

We thank A. Baldwin for his advice throughout this project and critical review of the manuscript.

This work was supported by National Institutes of Health grant RO1-CA48185 and a Jefferson Pilot Award to J. P.-Y. Ting. J.C. is a special fellow of the Leukemia Society of America. B.V. was supported by NIH-NIAID training grant P32-AI-07273.

\section{REFERENCES}

1. Baldwin, A. S. 1988. Methylation interference assay for analysis of DNA-protein interactions, p. 12.3.1-12.3.6. In F. M. Ausubel, R. Brent, R. E. Kingston, D. D. Moore, J. G. Seidman, J. A. Smith, and K. Struhl (ed.), Current protocols in molecular biology, vol. 2. Greene Publishing Associates and Wiley-Interscience, New York.

2. Basham, T. Y., and T. C. Merigan. 1983. Recombinant interferon- $\gamma$ increases HLA-DR synthesis and expression. J. Immunol. 130:1492-1495.

3. Basta, P. V., P. A. Sherman, and J. P.-Y. Ting. 1988. Detailed delineation of an interferon- $\gamma$-responsive element important in human HLA-DRA gene expression in a glioblastoma multiform line. Proc. Natl. Acad. Sci. USA 85:8618-8622.

4. Benacerraf, B. 1981 . Role of MHC gene products in immune regulation. Science 212:1229-1238.
5. Berk, A. J., and P. A. Sharp. 1977. Sizing and mapping of early adenovirus mRNAs by gel electrophoresis of $S_{1}$ endonucleasedigested hybrids. Cell 12:721-732.

6. Boothby, M. R., H.-C. Liou, and L. H. Glimcher. 1989. Differences in DNA sequence specificity among MHC class II X-box binding proteins. J. Immunol. 142:1005-1014.

7. Bottazzo, G. F., R. Pujol-Borrell, T. Hanafusa, and M. Feldmann. 1983. Role of aberrant HLA-DR expression and antigen presentation in induction of endocrine autoimmunity. Lancet ii:1115-1118.

8. Brown, A. M., C. L. Barr, and J. P.-Y. Ting. J. Immunol., in press.

9. Celada, A., and R. Maki. 1989. Evidence for multiple major histocompatibility class II X-box binding proteins. Mol. Cell. Biol. 9:5219-5222.

10. Chirgwin, J. M., A. E. Przybyla, R. J. MacDonald, and W. J. Rutter. 1979. Isolation of biologically active ribonucleic acid from sources enriched in ribonuclease. Biochemistry 18:5294 5299.

11. Cogswell, J. P., P. V. Basta, and J. P.-Y. Ting. 1990. X-box binding proteins positively and negatively regulate transcription of the HLA-DRA gene through interaction with discrete upstream W and V elements. Proc. Natl. Acad. Sci. USA 87:77037707.

12. Collins, T., A. J. Korman, C. T. Wake, J. M. Boss, D. J. Kappes, W. Fiers, K. A. Ault, M. A. Gimbrone, J. L. Strominger, and J. S. Pober. 1984. Immune interferon activates multiple class II major histocompatibility complex genes and the associated invariant chain gene in human endothelial cells and dermal fibroblasts. Proc. Natl. Acad. Sci. USA 81:4917-4921.

13. Dandanell, G., and K. Hammer. 1985. Two operator sites separated by 599 base pairs are required for deoR repression of the deo operon of Escherichia coli. EMBO J. 4:3333-3338.

14. Dedrick, R. L., and P. P. Jones. 1990 . Sequence elements required for activity of a murine major histocompatibility complex class II promoter bind common and cell-type-specific nuclear factors. Mol. Cell. Biol. 10:593-604.

15. Didier, D. K., J. Schiffenbauer, S. L. Woulfe, M. Zacheis, and B. D. Schwartz. 1988. Characterization of the cDNA encoding a protein binding to the major histocompatibility complex class II Y box. Proc. Natl. Acad. Sci. USA 85:7322-7326.

16. Dignam, J. D., R. M. Lebovitz, and R. G. Roeder. 1983 Accurate transcription initiation by RNA pol II in a soluble extract from isolated mammalian nuclei. Nucleic Acids Res. 11:1475-1489.

17. Dorn, A., U. Bollekens, A. Staub, C. Benoist, and D. Mathis. 1987. A multiplicity of CCAAT box-binding proteins. Cell 50:863-872.

18. Dorn, A., B. Durand, C. Marfing, M. LeMeur, C. Benoist, and D. Mathis. 1987. Conserved major histocompatibility complex class II boxes- $X$ and $Y$ are transcriptional control elements and specifically bind nuclear proteins. Proc. Natl. Acad. Sci. USA 84:6249-6253.

19. Doyle, C., P. J. Ford, P. D. Ponath, T. Spies, and J. L. Strominger. 1990. Regulation of the class II-associated invariant chain gene in normal and mutant B lymphocytes. Proc. Natl. Acad. Sci. USA 87:4590-4594.

20. Dunn, T. M., S. Hahn, S. Ogden, and R. F. Schleif. 1984. An operator at $\mathbf{- 2 8 0}$ base pairs that is required for repression of araBAD operon promoter: addition of DNA helical turns between the operator and promoter cyclically hinders repression. Proc. Natl. Acad. Sci. USA 81:5017-5020.

21. Eades, A.-M., M. Litfin, and H. J. Rahmsdorf. 1990. The IFN- $\gamma$ response of the murine invariant chain gene is mediated by a complex enhancer that includes several MHC class II consensus elements. J. Immunol. 144:4399-4409.

22. Fried, M., and D. M. Crothers. 1981. Equilibria and kinetics of lac repressor-operator interactions by polyacrylamide gel electrophoresis. Nucleic Acids Res. 9:6505-6525.

23. Garner, M. M., and A. Revzin. 1981. A gel electrophoresis method for quantifying the binding of proteins to specific DNA regions: application to components of the Escherichia coli lactose operon regulatory system. Nucleic Acids Res. 9:3047-3060. 
24. Griffith, J., A. Hochschild, and M. Ptashne. 1986. DNA loops induced by cooperative binding of $\lambda$ repressor. Nature (London) 322:750-752.

25. Hammerling, G. J. 1976. Tissue distribution of Ia antigens and their expression on lymphocyte subpopulations. Transplant. Rev. 30:64-82.

26. Hochschild, A., and M. Ptashne. 1986. Cooperative binding of $\lambda$ repressors to sites separated by integral turns of the DNA helix. Cell 44:681-687.

27. Hochschild, A., and M. Ptashne. 1988. Interaction at a distance between $\lambda$ repressors disrupts gene activation. Nature (London) 336:353-357.

28. Jones, N. C., D. W. J. Rigby, and E. W. Ziff. 1988. Trans-acting protein factors and the regulation of eukaryotic transcription: lessons from studies on DNA tumor viruses. Genes Dev. 2:267-281.

29. Kaufman, J. F., C. Auffray, A. J. Korman, D. A. Shackelford, and J. L. Strominger. 1984. The class II molecules of the human and murine major histocompatibility complex. Cell 36:1-13.

30. Kelly, A., and J. Trowsdale. 1985. Complete nucleotide sequence of a functional HLA-DP $\beta$ gene and the region between the DP $\beta 1$ and DP $\alpha 1$ genes: comparison of the $5^{\prime}$ ends of the HLA class II genes. Nucleic Acids Res. 13:1607-1621.

31. Koch, N., G. H. W. Wong, and J. W. Schrader. 1984. Ia antigens and associated invariant chain are induced simultaneously in lines of T-dependent mast cells by recombinant interferon- $\gamma$. J. Immunol. 132:1361-1369.

32. Korman, A. J., J. M. Boss, T. Spies, R. Sorrentino, K. Okada, and J. L. Strominger. 1985. Genetic complexity and expression of human class II histocompatibility antigens. Immunol. Rev. $85: 45-86$.

33. Liou, H.-C., M. R. Boothby, P. W. Finn, R. Davidson, N. Nabave, N. J. Zeleznik-Le, J. P.-Y. Ting, and L. H. Glimcher. 1990. A new member of the leucine zipper class of proteins that binds to the HLA-DR $\alpha$ promoter. Science 247:1581-1584.

34. Liou, H.-C., M. R. Boothby, and L. H. Glimcher. 1988. Distinct cloned class II MHC DNA binding proteins recognize the $\mathrm{X}$ box transcription element. Science 242:69-71.

35. Long, E. O., B. Mach, and R. S. Accolla. 1984. Ia-negative B-cell variants reveal a coordinate regulation in transcription of the HLA class II gene family. Immunogenetics 19:349-353.

36. Majumdar, A., and S. Adhya. 1984. Demonstration of two operator elements in gal: in vitro repressor binding studies. Proc. Natl. Acad. Sci. USA 81:6100-6104.

37. Maniatis, T., S. Goodborn, and J. A. Fischer. 1987. Regulation of inducible and tissue-specific gene expression. Science 236: 1237-1245.

38. Massa, P. T., V. ter Meulen, and A. Fontana. 1987. Hyperinducibility of Ia antigen on astrocytes correlates with strainspecific susceptibility to experimental autoimmune encephalomyelitis. Proc. Natl. Acad. Sci. USA 84:4219-4223.

39. McKnight, S. L. 1982. Functional relationship between transcriptional control signals of the thymidine kinase gene of herpes simplex virus. Cell 31:355-365.

40. Melton, D. A., P. A. Krieg, M. R. Rebagliati, T. Maniatis, K. Zinn, and M. R. Green. 1984. Efficient in vitro synthesis of biologically active RNA and RNA hybridization probes from plasmids containing a bacteriophage SP6 promoter. Nucleic Acids Res. 12:7035-7056.

41. Mitchell, P. J., and R. Tjian. 1989. Transcriptional regulation in mammalian cells by sequence specific DNA binding proteins. Science 245:371-378.

42. Miwa, K., C. Doyle, and J. L. Strominger. 1987. Sequence specific interactions of nuclear factors with conserved sequences of human class II major histocompatibility complex genes. Proc. Natl. Acad. Sci. USA 84:4939-4943.

43. Pape, L. K., J. J. Windle, and B. Sollner-Webb. 1990. Half helical turn spacing changes convert a frog into a mouse rDNA promoter: a distant upstream domain determines the helix face of the initiation site. Genes Dev. 4:52-62.

44. Paulnock-King, D., K. C. Sizer, Y. R. Freund, P. P. Jones, and J. R. Parnes. 1985. Coordinate induction of the Ia $\alpha, \beta$ and Ii
mRNA in a macrophage cell line. J. Immunol. 135:632-636.

45. Pober, J. S., T. Collins, R. S. Gimbrone, R. S. Cotran, J. D. Gitlin, W. Fiers, C. Clayberger, H. M. Krensky, S. J. Burakofi, and C. S. Reiss. 1983. Lymphocytes recognize human vascular endothelial and dermal fibroblast la antigens induced by recombinant immune-interferon. Nature (London) 305:726-729.

46. Ptashne, M. 1986 . Gene regulation by proteins acting nearby and at a distance. Nature (London) 322:697-701.

47. Ptashne, M. 1988. How eukaryotic transcriptional activators work. Nature (London) 335:683-689.

48. Pugh, B. F., and R. Tjian. 1990. Mechanism of transcriptional activation by Spl: evidence for coactivators. Cell 61:1187-1197.

49. Pujol-Borrell, R., I. Todd, M. Doshi, G. F. Bottazzo, R. Sutton, D. Gray, G. R. Adolf, and M. Feldmann. 1987. HLA class II induction in human islet cells by interferon- $\gamma$ plus tumour necrosis factor or lymphotoxin. Nature (London) 326:304-306.

50. Reith, W., E. Barras, S. Satola, M. Kobr, D. Reinhart, C. Herrero Sanchez, and B. Mach. 1989. Cloning of the major histocompatibility complex class II promoter binding protein affected in a hereditary defect in class II gene regulation. Proc. Natl. Acad. Sci. USA 86:4200-4204.

51. Robbins, P. A., V. C. Maino, N. L. Warner, and F. M. Brodsky. 1988. Activated $T$ cells and monocytes have characteristic patterns of class II antigen expression. J. Immunol. 141:12811287.

52. Rosenthal, A. S., and E. Shevach. 1973. Function of macrophages in antigen recognition by guinea pig $\mathrm{T}$ lymphocytes. $\mathrm{J}$. Exp. Med. 138:1194-1212.

53. Sakurai, M., and J. L. Strominger. 1988. B-cell-specific enhancer activity of conserved upstream elements of the class II major histocompatibility complex DQB gene. Proc. Natl. Acad. Sci. USA 85:6909-6913.

54. Schwartz, R. H. 1986. Immune response (Ir) genes of the murine major histocompatibility complex. Adv. Immunol. 38:31-201.

55. Sherman, P. A., P. V. Basta, T. L. Moore, A. M. Brown, and J. P.-Y. Ting. 1989. Class II box consensus sequences in the HLA-DRA gene: transcriptional function and interaction of nuclear proteins. Mol. Cell. Biol. 9:50-56.

56. Sherman, P. A., P. V. Basta, and J. P.-Y. Ting. 1987. Upstream DNA sequences required for tissue-specific expression of the HLA-DRA gene. Proc. Natl. Acad. Sci. USA 84:4254-4258.

57. Sprent, J., D. Lo, E.-K. Gao, and Y. Ron. 1988. T cell selection in the thymus. Immunol. Rev. 101:173-190.

58. Takahashi, K., M. Vigneron, H. Matthes, A. Wildeman, $M$. Zenke, and P. Chambon. 1986. Requirement of stereospecific alignments for initiation from the simian virus $\mathbf{4 0}$ early promoter. Nature (London) 319:121-126.

59. Ting, J. P.-Y., B. L. Shigekawa, D. S. Linthicom, L. P. Weiner, and J. A. Frelinger. 1981. Expression and synthesis of murine immune response-associated (Ia) antigens by brain cells. Proc. Natl. Acad. Sci. USA 78:3170-3179.

60. Triezenberg, S. J., R. C. Kingsbury, and S. L. McKnight. 1988. Functional dissection of VP16, the transactivator of herpes simplex immediate early gene expression. Genes Dev. 2:718729.

61. Tsang, S. Y., M. Nakanishi, and B. M. Peterlin. 1990. Mutational analysis of the DRA promoter: cis-acting sequences and transacting factor. Mol. Cell. Biol. 10:711-719.

62. Waibel, F., and W. Filipowicz. 1990. RNA-polymerase specificity of transcription of Arabidopsis U snRNA genes determined by promoter element spacing. Nature (London) 346:199 202.

63. Wu, L., and A. Berk. 1988. Constraints on spacing between transcription factors binding in a simple adenovirus promoter. Genes Dev. 2:403-411.

63a.Zeleznik-Le, N. J. Personal communication.

64. Zeleznik-Le, N. J., J. C. Azizkhan, and J. P.-Y. Ting. Proc. Natl. Acad. Sci. USA, in press.

65. Zhu, L., and P. P. Jones. 1990. Transcriptional control of the invariant chain gene involves promoter and enhancer elements common to and distinct from major histocompatibility complex class II genes. Mol. Cell. Biol. 10:3906-3916. 